\title{
Influence of a mixture of metals on PAHs biodegradation processes in soils
}

3. Oriol Baltrons ${ }^{a}$, Montserrat López-Mesas ${ }^{*} a$, Mercè Vilaseca ${ }^{b}$, Carmen Gutiérrez-Bouzán ${ }^{b}$, Franck Le ${ }_{4}$ Derf $^{c}$, Florence Portet-Koltalo ${ }^{c}$, Cristina Palet ${ }^{a}$

${ }_{6}{ }^{a}$ Centre Grup de Tècniques de Separació en Química (GTS), Edifici CN, Universitat Autònoma de ᄀ Barcelona, 08193 Bellaterra, Barcelona, Spain.

${ }_{8}^{b}$ Laboratori de Control de la Contaminació Ambiental, Institut d'Investigació Tèxtil i Cooperació 9. Industrial de Terrassa (INTEXTER), Edifici TR7, Carrer Colom, 15, 08222, Terrassa, Spain

${ }_{10}{ }^{c} U M R 6014$ COBRA, Université de Rouen, 55 Rue Saint Germain, 27000 Évreux, France.

${ }_{12}$ * Corresponding author: Montserrat López-Mesas

${ }_{13}$ Address: Centre Grup de Tècniques de Separació en Química (GTS), Edifici CN, Universitat

14 Autònoma de Barcelona, 08193 Bellaterra, Barcelona, Spain

15 Phone number: +34935814938

${ }_{16} \quad$ E-mail address: montserrat.lopez.mesas@uab.cat

${ }_{17}^{1}$ Currently at: CNRS / Univ Pau \& Adour, Institut des sciences analytiques et de physico-chimie pour ${ }_{18}$ l'environnement et les matériaux, UMR5264, 64000 Pau, France. 
${ }_{22}$ In order to assess the effect of mixed pollutants, the influence of different concentration levels of a ${ }_{23}$ mixture of metals $(\mathrm{Cr}, \mathrm{Co}, \mathrm{Pb}, \mathrm{Mn}, \mathrm{Ni}, \mathrm{Cu}, \mathrm{Zn})$ on the biodegradation of some PAHs (phenanthrene, ${ }_{24}$ fluoranthene, pyrene, benzo $[b]$ fluoranthene and benzo[a]pyrene) in soil samples was evaluated. To do ${ }_{25}$ So, groups of microcosms of a natural soil from the region of Sabadell (Barcelona, Spain) were ${ }_{26}$ prepared as a reproduction of the native environment at laboratory scale, under controlled conditions. ${ }_{27}$ Mixtures of PAHs and metals were carefully selected, according to soil characterization and ${ }_{28}$ microbiological growth preliminary assays, and were added to microcosms. These microcosms were ${ }_{29}$ analyzed at various times, along two months, to obtain PAHs dissipation time-courses. A first-order ${ }_{30}$ kinetic modelling allowed obtaining different rate constants and DT50 values as a function of the ${ }_{31}$ metal levels introduced in microcosms. As a general observation, the higher the concentration of ${ }_{32}$ metals, the lower the biodegradation of PAHs of 3-4 rings (phenanthrene, fluoranthene and pyrene).

${ }_{33}$ On the other hand, no important effect on the biodegradation of higher molecular weight PAHs ${ }_{34}$ (benzo[b]fluoranthene and benzo[a]pyrene) was observed at the different concentration levels of ${ }_{35}$ metals tested.

\section{${ }_{37}$ Keywords}

${ }_{38}$ Polycyclic aromatic hydrocarbons, metals, co-contamination, microcosms, biodegradation, soils. 
${ }_{41} 1$ Introduction

${ }_{43}$ Nowadays it is well-known that harmful toxic pollutants such as polycyclic aromatic hydrocarbons ${ }_{44}$ (PAHs) and heavy metals contribute to the pollution of the biosphere, which has been dramatically 4s accelerated since the industrial revolution (Chen et al., 2015). PAHs are a wide group of organic ${ }_{46}$ pollutants produced by the incomplete combustion of organic matter at high temperatures (Wilson and ${ }_{47}$ Jones, 1993). They are carcinogenic and mutagenic. They are constituted of two or more fused ${ }_{48}$ benzene rings and are found in water, air, soils, food, etc. PAHs accumulate in soils principally after ${ }_{49}$ atmospheric deposition mechanisms (Tobiszewski and Namienik, 2012). Metals can be found in the ${ }_{50}$ earth's crust, soils and vegetation, and many of them are essential for the development of living ${ }_{51}$ organisms but can become toxic if they exceed certain thresholds (Huertos and Baena, 2008; Zehetner ${ }_{52}$ et al., 2009).

${ }_{53}$ PAHs in soils are known to degrade into metabolites through different paths. In general, ${ }_{54}$ biodegradation of organic substances in soil involves a complex community of bacteria and fungi with ${ }_{55}$ numerous enzymatic pathways (Deary et al., 2016). The main mechanism of PAHs degradation in soils ${ }_{56}$ is naturally controlled by microorganisms like Pseudomonas, Burkholderia cepacia, Sphingomonas, ${ }_{57}$ Flavobacterium, Acinetobacter (Siddiqi et al., 2002; Watanabe, 2001; Zhou et al., 2016; Janbandhu ${ }_{58}$ and Fulekar, 2011), other groups such as actinomycetes (Samanta et al., 2002), white-rot fungi (Boyle ${ }_{59}$ et al., 1998; Fernández-Luqueño et al. 2011), an acid-metal-tolerant Trabulsiella, among others ${ }_{60}$ (Kuppusamy et al. 2016a). A native microbial consortium (instead of a single degrader) has been also ${ }_{61}$ checked recently (Biswas et al., 2015; Kuppusamy et al., 2016b). Furthermore, photooxidation and ${ }_{62}$ other chemical reactions (such as Fenton-like reactions) can also take place (Jonsson et al., 2007; Tam ${ }_{63}$ et al., 2008). 
${ }_{64}$ There are studies which showed that metals can have an effect on microbial communities, inducing ${ }_{65}$ changes on the size, growth and activity (Giller et al., 1998) as well as reducing the availability of ${ }_{66}$ substrates used for respiration or causing acute toxicity leading to their death (Landi et al., 2000). ${ }_{67}$ Therefore, scientists agreed that these pollutants could have a negative effect on the biodegradation of ${ }_{68}$ organic compounds (such as PAHs) through the inhibition of the enzymatic activity involved in these ${ }_{69}$ processes.

${ }_{70}$ There are several reported studies which highlight the problem of the mixed contamination of PAHs ${ }_{71}$ and heavy metals (Subashchandrabose et al., 2015). The toxicity of mixtures of PAHs and metals can 72 show synergistic or antagonist effects on toxicity and/or enzymatic activity, depending on the nature ${ }_{73}$ and relative concentration, of these pollutants (Moreau et al., 1999; Shen et al., 2006, 2005; ${ }_{74}$ Thavamani et al., 2012; Biswas et al., 2015). About the effect of PAH/metal mixtures, some authors ${ }_{75}$ reported an absence of biodegradation of anthracene in the presence of $\mathrm{Pb}$ (Fualkowska et al., 1998) or ${ }_{76}$ a decrease in the mineralization of Phe when communities were exposed to $\mathrm{Cu}$ (Sokhn et al., 2001). ${ }_{77}$ Others, reported higher degradation rates for $\mathrm{Pyr} / \mathrm{Pb}$ mixtures (30 and $300 \mathrm{mg} \mathrm{kg}^{-1}$, respectively) than ${ }_{78}$ for isolated $\mathrm{Pyr}\left(30 \mathrm{mg} \mathrm{kg}^{-1}\right)$, suggesting that $\mathrm{Pb}$ promotes bacterial growth through the detoxification ${ }_{79}$ of Pyr, resulting in a higher degradation of this PAH (Khan et al., 2009). Some authors had also seen ${ }_{80}$ that $\mathrm{Zn}$ could enhance the mineralization of Phe (Moreau et al., 1999), while other studies indicated ${ }_{81}$ that the presence of $\mathrm{Zn}\left(50-1,000 \mathrm{mg} \mathrm{kg}^{-1}\right)$ and $\mathrm{Cu}\left(50-100 \mathrm{mg} \mathrm{kg}^{-1}\right)$ did not induce any significant ${ }_{82}$ effects on its degradation, but higher amounts of $\mathrm{Cu}$ caused a decrease in the biodegradation capability ${ }_{83}$ via reduction of dehydrogenase activity (Obuekwe and Semple, 2013). Most of these effects were ${ }_{84}$ observed in studies conducted under in vitro conditions, which is useful for the evaluation of specific ${ }_{85}$ effects, for example, on enzymatic activities. However, in such cases, interactions with the ${ }_{86}$ environmental matrices where biodegradation processes take place were not considered and could be ${ }_{87}$ certainly significant. Consequently, other authors have studied the effect of metals such as $\mathrm{Cd}, \mathrm{Hg}, \mathrm{Pb}$, ${ }_{88} \mathrm{Zn}, \mathrm{Cu}, \mathrm{Ni}$ on the degradation of mixtures of PAHs in the corresponding environmental matrices, 
${ }_{89}$ finding significant differences depending on the experimental conditions tested (Baldrian et al., 2000; ${ }_{90}$ Ke et al., 2010; Khan et al., 2009; Biswas et al., 2015; Deary et al., 2016). Other studies, show the ${ }_{91}$ biodegradation evaluation of one $\mathrm{PAH}$ in the presence of a mixture of heavy metal solutions at ${ }_{92}$ different $\mathrm{pH}$ (Kuppusamy et al. 2016b) and the comparison of the simultaneous biodegradation of two ${ }_{93}$ PAHs in the presence of individual metal solutions of $\mathrm{Zn}, \mathrm{Pb}, \mathrm{Cu}$ and $\mathrm{Cd}$ (Kuppusamy et al. 2016a).

${ }_{94}$ The main objective of the present work is to study the influence of different concentrations of a ${ }_{95}$ mixture of metals on the biodegradation of some PAHs, under controlled conditions (i.e. temperature, ${ }_{96}$ light exposure, humidity, etc.). Contrary to evaluating specific single-metal/PAH interactions, focusing ${ }_{97}$ On mixtures allows to have a global picture of the mixed pollutants impact in the native soil. Hence, a ${ }_{98}$ group of soil based microcosms were prepared, spiked with a selected mixture of PAHs and different ${ }_{99}$ concentration levels of a mixture of metals. First, the selected soil was characterized in order to decide ${ }_{100}$ the concentration of PAHs to be added to the microcosms and to determine the original bioavailable ${ }_{101}$ metal content. Secondly, bacterial growth assays were performed in order to choose the range of metal ${ }_{102}$ concentration levels to be studied. Finally, microcosms were prepared and analyzed to carry out the ${ }_{103}$ biodegradation experiments to accomplish the aforementioned main objective.

${ }_{105} 2$ Experimental

106

\section{${ }_{107} 2.1$ Chemicals}

108

${ }_{109}$ Toluene, acetone (HPLC grade) and nitric acid (69.5\%) were obtained from Sigma-Aldrich ${ }_{110}$ (Barcelona, Spain) and hydrochloric acid (37\%) from Panreac (Barcelona, Spain). Water was purified ${ }_{111}$ and deionized using an Elga Classic system from Veolia Water Solutions and Technology (Madrid, ${ }_{112}$ Spain). The internal standard, perdeuterated phenanthrene (Phe- $\left.\mathrm{D}_{10}\right)$ and five PAHs used to spike ${ }_{113}$ microcosms (phenanthrene, fluoranthene, pyrene, benzo[a]pyrene, benzo[b]fluoranthene) were 
${ }_{114}$ purchased from Sigma-Aldrich (Madrid, Spain). A stock solution of the PAHs was prepared in ${ }_{115}$ acetone. Nitrate metal salts (cobalt, chromium, manganese, lead, zinc), copper sulfate and magnesium ${ }_{116}$ chloride were acquired from Merck (Madrid, Spain). All reagents were of analytical grade. Stocks ${ }_{117}$ solutions were prepared in diluted nitric acid in ultrapure deionized water. Ringer Oxoid BR52 was ${ }_{118}$ purchased from ThermoFisher Scientific (Barcelona, Spain) and Triptic Soy Agar from Scharlab ${ }_{119}$ (Barcelona, Spain), used for bacterial culture assays.

\section{${ }_{121} 2.2$ Collection and characterization of soil samples}

122

${ }_{123}$ Soil samples were collected in March 2013 in Sabadell (Catalonia, Spain). The winter rainfall was of ${ }_{124}$ less than $25 \mathrm{~mm}$ (official data by Servei Meteorològic de Catalunya, Generalitat de Catalunya, Spain). ${ }_{125}$ Sampling point was nearby the area of Ripoll's river $\left(41^{\circ} 31^{\prime} 57.62^{\prime} \mathrm{N}, 2^{\circ} 07^{\prime} 35.06^{\prime} \mathrm{E}\right)$, an area of ${ }_{126}$ Sparsely populated scrubland with irregular cover and mainly surrounded by textile industries (Figure $\left.{ }_{127} 1\right)$. About $10 \mathrm{~kg}$ of soil were collected from the upper horizontal layer $(0-25 \mathrm{~cm})$. The sample was ${ }_{128}$ passed through a $2 \mathrm{~mm}$ stainless steel sieve to remove large debris and $1 \mathrm{~kg}$ was separated and used for ${ }_{129}$ characterization experiments. A nested column of sieves with wire mesh cloth of different diameters ${ }_{130}$ Was used to assess soil's particle size distribution. According to the Soil Taxonomy (U. S. Department ${ }_{131}$ of Agriculture, 1999), the soil is an Inceptisol (Typic Haplustepts), with coarse sandy soil containing ${ }_{132} 94 \%$ of sand (24\% very coarse sand, $21 \%$ coarse sand, $20 \%$ medium sand, $1 \%$ fine sand and $28 \%$ ${ }_{133}$ very fine sand) and $6 \%$ of silt and clay (5\% coarse silt and $1 \%$ smaller particles) (Wentworth, 1922). ${ }_{134}$ Moisture content was $1.9 \pm 0.2 \%$, determined as the relative weight difference after drying $3.5 \mathrm{~g}$ of ${ }_{135}$ sample at $115^{\circ} \mathrm{C}$ for $24 \mathrm{~h}$, until constant weight was reached (less than $0.1 \%$ weight difference ${ }_{136}$ between two successive weightings within a $4 \mathrm{~h}$ time interval). Similarly, organic matter $(0.9 \pm 0.2 \%)$ ${ }_{137}$ Was determined as the relative weight difference after calcination of $2.5 \mathrm{~g}$ of dry sample at $500{ }^{\circ} \mathrm{C}$ ${ }_{138}$ during $4 \mathrm{~h}$ until constant weight was reached. The $\mathrm{pH}$ was $7.8 \pm 0.1$, obtained from the potentiometric 
${ }_{139}$ measure of an extract of soil:water (1:2.5), after $30 \mathrm{~min}$ of mechanical shaking. The maximum water ${ }_{140}$ holding capacity (MWHC) was $32 \pm 1 \%$, according to humidity determination of a $250 \mathrm{~g}$ water${ }_{141}$ Saturated soil column. Carbonate ions content reached $6 \pm 1 \%$, calculated as the amount of $\mathrm{CO}_{2}$ ${ }_{142}$ generated in a calcimeter, after the addition of hydrochloric acid. Electrical conductivity (194 $\pm 7 \mu \mathrm{S}$ ${ }_{143} \mathrm{~cm}^{-1}$ ) was obtained by the conductometric measurement of an extract of soil:water $(1: 10)$, after $2 \mathrm{~h}$ of ${ }_{144}$ mechanical shaking. The total concentration of bioavailable metals was $1.5 \pm 0.1 \mathrm{mg} \mathrm{kg}^{-1}$ (see section ${ }_{145} 2.7$ ), the total background amount of the five selected PAHs was $264 \pm 12 \mu \mathrm{g} \mathrm{kg}^{-1}$ (see section 2.5 ), and ${ }_{146}$ the number of colony forming units $(\mathrm{CFU})$ was $(1.5 \pm 0.4) \times 10^{4} \mathrm{CFU} \mathrm{g}{ }^{-1}$. CFU were determined by ${ }_{147}$ preparation of a series of dilutions of an aqueous soil extract (in Ringer solution) inoculated with a ${ }_{148}$ Digralsky spreader in tryptic soy agar growth media poured into Petri dishes. Then, incubation was ${ }_{149}$ performed at $30{ }^{\circ} \mathrm{C}$ during $48 \mathrm{~h}$, previous to CFU counting. All the material employed was previously ${ }_{150}$ sterilized in an autoclave.

${ }_{151}$ The rest of the sample was stored at $20{ }^{\circ} \mathrm{C}$ for one week (under humidity control). Then, $10 \%$ of the ${ }_{152}$ collected soil was sterilized by autoclaving, dried one night at $35{ }^{\circ} \mathrm{C}$ and softly crushed. This fraction ${ }_{153}$ was used to spike PAHs in the preparation of the microcosms.

${ }_{154}$ The soil of Sabadell was selected after characterization and preliminary biodegradation assays of three ${ }_{155}$ different soils collected from two other villages on the same day. The soil of Sabadell was located ${ }_{156}$ nearby an industrial area and had been stable for more than 20 years, whereas the others had been ${ }_{157}$ potentially impacted by nearby highway construction and agricultural activities. Initial tests involving 158 the preparation of some microcosms revealed that the number of colony forming units was more ${ }_{159}$ abundant in Sabadell's soil and the ability of microorganisms to degrade PAHs was also more ${ }_{160}$ efficient. Furthermore, Sabadell's soil is drier in comparison to the other soils, and humidity can be a ${ }_{161}$ limiting factor for PAHs desorption. In this regard, due to the hydrophobic nature of PAH and poor 
${ }_{162}$ mass transfer of PAH to bacterial cells (Zhang et al., 2006; Kobayashi et al., 2009), less PAH ${ }_{163}$ bioavailability was expected for the more humid soils.

${ }_{164}$ All this information contributed to the decision of choosing the soil of Sabadell as the more suitable ${ }_{165}$ for this work.

${ }_{167} 2.3$ Selection of spiking concentrations for PAHs and metals

168

${ }_{169}$ To select the metals and PAHs of the study, an initial screening of their content in the sample was ${ }_{170}$ performed by ICP/MS and GC/MS, respectively. Then, they were selected according to the total ${ }_{171}$ concentration found in the soil, and its representativeness in other contaminated soil studies (Blum et 172 al., 2009; Kabata-Pendias, 2010; Wuana and Okieimen, 2011; Crampon et al., 2014). Metals were also ${ }_{173}$ selected according to the concentration found in the exchangeable fraction (bioavailable) (sections 2.7 ${ }_{174}$ and 3.1), and PAHs to have different molecular weights also represented (3, 4 and 5rings).

${ }_{175}$ Five representative PAHs were selected to conduct the biodegradation studies: phenanthrene (Phe) ${ }_{176}$ (three rings), fluoranthene (Fluo) and pyrene (Pyr) (four rings) and benzo[b]fluoranthene (BbF) and ${ }_{177}$ benzo[a]pyrene $(\mathrm{BaP})$ (five rings). The concentration of PAHs which was spiked into microcosms was ${ }_{178}$ selected according to the previously PAH content found in soil, following other related biodegradation ${ }_{179}$ studies (Baltrons et al., 2013; Niepceron et al., 2013) where soils were typically spiked at a ${ }_{180}$ concentration of 100-10,000 times to that found in soil.

${ }_{181}$ To select the spiking concentrations of metals, microbiological assays were carried out to assess ${ }_{182}$ possible impacts on bacterial growth. To do so, nine portions of $100 \mathrm{~g}$ of fresh native collected soil ${ }_{183}$ were prepared. Eight of them were spiked to reach a concentration of 2, 5, 10, 50, 100, 250, 500 and ${ }_{184} 1,000$ times the bioavailable metals concentration found in soil. The ratio of the bioavailable metals ${ }_{185}$ concentration found in the native soil was preserved. Metals were introduced in $22.1 \mathrm{~mL}$ of deionized ${ }_{186}$ sterile water. The ninth portion was not spiked (in order to observe microorganisms growth under the 
${ }_{187}$ native bioavailable concentration of the metals found in soil), and $22.1 \mathrm{~mL}$ of sterilized water was also 188 added. After this, samples were kept under temperature and humidity control during five days for 189 stabilization. Then, fifty-four incubation experiments (including duplicates) in Petri dishes were ${ }_{190}$ performed. To do so, bacteria from $1.0 \mathrm{~g}$ of each of the nine portions of soil (containing the different ${ }_{191}$ concentrations of metals) was extracted with $100 \mathrm{~mL}$ of sterile deionized water for 30 min, under ${ }_{192}$ stirring. Then, series of dilutions $(1: 10 ; 1: 100$ and $1: 1,000)$ of the main extract were prepared in Ringer ${ }_{193}$ solution and $0.1 \mathrm{~mL}$ was poured into nutrient agar and incubated at $30^{\circ} \mathrm{C}$ for $48 \mathrm{~h}$. The nutrient agar ${ }_{194}$ was prepared by dissolving $40.0 \mathrm{~g}$ of Tryptic Soy Agar (TSA) in $1 \mathrm{~L}$ of water. All the material used ${ }_{195}$ was sterilized by autoclaving at $120^{\circ} \mathrm{C}$ during $20 \mathrm{~min}$.

196

\subsection{Preparation of microcosms}

198

${ }_{199}$ Microcosms were prepared in $200 \mathrm{~mL}$ sterilized glass flasks. Each one was filled with $10 \mathrm{~g}$ of dry ${ }_{200}$ Sterile soil and spiked to reach a total concentration of $1,000 \mathrm{mg} \mathrm{kg}^{-1}$ of the five selected PAHs (200 ${ }_{201} \mathrm{mg} \mathrm{kg}^{-1}$ of each PAH). They were shaken under an extractor hood for $48 \mathrm{~h}$ to better distribute PAHs ${ }_{202}$ and evaporate acetone (solvent used to dissolve PAHs). After a week of stabilization, dry sterilized ${ }_{203}$ soils enriched with PAHs were mixed with $91.7 \mathrm{~g}$ wet native soil (equivalent to $90 \mathrm{~g}$ of dry soil) and ${ }_{204}$ homogenized to obtain microcosms. Therefore, final PAHs concentration in microcosms was $100 \mathrm{mg}$ ${ }_{205} \mathrm{~kg}^{-1}$. Then, metals were introduced at the desired concentration dissolved in $22.1 \mathrm{~mL}$ of sterile ${ }_{206}$ deionized water to reach the $60 \%$ of MWHC, and the system was homogenized again (see Figure 2, a ${ }_{207}$ Scheme of microcosms preparation). Finally, the glass flasks were hermetically closed and incubated at ${ }_{208} 20^{\circ} \mathrm{C}$ in static mode in a dark room with aeration (opening the flasks $1 \mathrm{~h}$ per day). Microcosms were ${ }_{209}$ divided into five different groups depending on the metal content added. Each group consisted of eight ${ }_{210}$ microcosms (one for each time of analysis: 0, 3, 7, 10, 15, 21, 30 and 60 days), prepared in duplicates. ${ }_{211}$ The first group of microcosms was not spiked with metals (corresponding to the native bioavailable 
${ }_{212}$ concentration of metals found in soil). Three more groups of microcosms were prepared by spiking ${ }_{213}^{2}$ different concentrations of metals to reach a final concentration of 10, 250 and 500 times the ${ }_{214}$ bioavailable concentration of metals naturally found in the soil. The last group was used as blank, ${ }_{215}$ consisting of $100 \mathrm{~g}$ of dry sterile soil spiked with PAHs to reach a final concentration of $100 \mathrm{mg} \mathrm{kg}^{-1}$ ${ }_{216}$ and $22.1 \mathrm{~mL}$ of sterile deionized water with the intermediate level of metals (x250).

217

${ }_{218} 2.5$ Microwave assisted extraction of PAHs from soil

219

${ }_{220}$ Microwave assisted extraction (MAE) was performed using a MARS X equipment (CEM Corporation, ${ }_{221}$ Matthews, USA). Wet soils from microcosms were previously dried one night at $35^{\circ} \mathrm{C}$ and then ${ }_{222}$ crushed. Before the extraction, perdeuterated phenanthrene (Phe- $\left.\mathrm{D}_{10}\right)$ was added as internal standard to ${ }_{223}$ reach a final concentration of $1.0 \mathrm{mg} \mathrm{L}^{-1}$. A sample size of $1.5 \mathrm{~g}$ of crushed dry soil was extracted ${ }_{224}$ using $25 \mathrm{~mL}$ of acetone:toluene (1:1) during 30 minutes at $140{ }^{\circ} \mathrm{C}$ and $1200 \mathrm{~W}$. Then, extracts were ${ }_{225}$ filtered through $0.22 \mu \mathrm{m}$ PVDF filters (Tianjin Heiaon Technology, Tianjin, China) in order to remove ${ }_{226}$ Soil particles prior to the analysis. PAHs recoveries were found between $95-102 \%$.

227

${ }_{228} 2.6 \mathrm{GC} / \mathrm{MS}$ analysis of PAHs

229

${ }_{230}$ After MAE, $1 \mu \mathrm{L}$ of the filtered extract was injected (pulsed splitless injection at $275{ }^{\circ} \mathrm{C}$ ) by an ${ }_{231}$ autosampler (Triplus) in a gas chromatographer (Trace GC Ultra) coupled to a mass spectrometer ${ }_{232}$ (DSQ II) from ThermoFisher Scientific (Barcelona, Spain). The column used was a TRACE TR-5MS ${ }_{233} 5 \%$ poly(phenylsilphenylen)siloxane $(30 \mathrm{~m} \times 0.25 \mathrm{~mm} \times 0.25 \mu \mathrm{m})$ from ThermoFisher Scientific ${ }_{234}$ (Barcelona, Spain). The oven program started at $60{ }^{\circ} \mathrm{C}\left(5 \mathrm{~min}\right.$ isothermal) increasing to $290{ }^{\circ} \mathrm{C}$, at $8{ }^{\circ} \mathrm{C}$ ${ }_{235} \min ^{-1}$ (2 min isothermal), under a constant carrier gas flow $(\mathrm{He})$ of $1.5 \mathrm{~mL} \mathrm{~min}^{-1}$. Ionization source 
${ }_{236}$ temperature was set at $225^{\circ} \mathrm{C}$ (electron impact, $70 \mathrm{eV}$ ) and the transfer line at $300{ }^{\circ} \mathrm{C}$. The detection of ${ }_{237}$ the analytes was conducted in selected ion monitoring (SIM), with the following selected masses: Phe${ }_{238} \mathrm{D}_{10}(188)$ as internal standard, Phe $(178,179,176)$, Fluo $(202,201,203)$, Pyr $(202,200,203)$ and BbF ${ }_{239}$ and $\mathrm{BaP}(252,253,125)$. The detection and quantification limits of the complete method (MAE${ }_{240} \mathrm{GC} / \mathrm{MS}$ ) were respectively 3.0/10.0 $\mathrm{ng} \mathrm{g}^{-1}$ for Phe, 4.9/16.1 $\mathrm{ng} \mathrm{g}^{-1}$ for Fluo and Pyr, 50.0/165.0 $\mathrm{ng} \mathrm{g}^{-1}$ ${ }_{241}$ for $\mathrm{BbF}$ and $94.2 / 314.0 \mathrm{ng} \mathrm{g}^{-1}$ for BaP. They were calculated as three and ten times the standard ${ }_{242}$ deviation of the blank sample noise area, respectively, after the extraction and analysis. The software ${ }_{243}$ used for data treatment was Xcalibur v.2.6.2.

244

${ }_{245}$ 2.7 Metal extraction from soil and ICP/MS analysis

246

${ }_{247}$ The bioavailable fraction of metals in the native soil was determined using $\mathrm{MgCl}_{2}$ as a single ${ }_{248}$ extracting solution. The extract, representing the exchangeable fraction, includes the metals adsorbed ${ }_{249}$ in the solid surfaces by weak electrostatic interactions and metals that can be released by ion exchange ${ }_{250}$ processes. It is accepted that the use of $\mathrm{MgCl}_{2}$ in single extractions constitutes a quick method to ${ }_{251}$ estimate the bioavailable metal content in soil (Bakircioglu et al., 2011). Hence, a mixture of 252 Soil: $\mathrm{MgCl}_{2} 0.1 \mathrm{~mol} \mathrm{~L}^{-1}(1: 8)$ was agitated for $1 \mathrm{~h}$, at room temperature, centrifuged for 15 min at 2,500 ${ }_{253} \mathrm{rpm}$ and filtered through $0.22 \mu \mathrm{m}$ PVDF filters. The supernatant was later analyzed by ICP/MS ${ }_{254}($ Elemental X Series 2), with an autosampler (CETAC ASX520), from ThermoFisher Scientific ${ }_{255}$ (Barcelona, Spain). Monoelemental metal solutions were used to prepare the standards in $2 \%$ nitric ${ }_{256}$ acid for the instrument calibration. Total dissolved solids (TDS) were fixed under $0.5 \%$ to minimize ${ }_{257}$ depositions on skimmer and sampling cones. Sc, Ga, In and $\mathrm{Tl}$ were used as internal standards at a ${ }_{258}$ concentration of $5 \mu \mathrm{g} \mathrm{L}^{-1}$. Determinations were done in triplicate and lines were rinsed during $1 \mathrm{~min}$ at

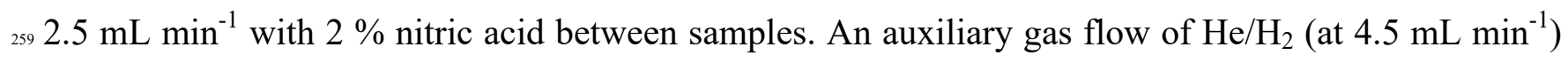
${ }_{260}$ Was used in the collision cell to reduce interferences, principally formed as a result of species 
${ }_{261}$ recombination (e.g. ${ }^{40} \mathrm{Ar}^{12} \mathrm{C}^{+}$interferes with ${ }^{52} \mathrm{Cr}$ ). The detection and quantification limits of the ${ }_{262}$ method (extraction-ICP/MS) were respectively $0.8 / 2.6 \mathrm{ng} \mathrm{g}^{-1}$ for $\mathrm{Cr}$, $\mathrm{Co}$ and $\mathrm{Pb}, 3.2 / 10.6 \mathrm{ng} \mathrm{g}^{-1}$ for $\mathrm{Mn}$, ${ }_{263}$ 2.4/7.9 $\mathrm{ng} \mathrm{g}^{-1}$ for $\mathrm{Ni}, 4.0 / 13.2 \mathrm{ng} \mathrm{g}^{-1}$ for $\mathrm{Cu}$ and 7.2/23.8 $\mathrm{ng} \mathrm{g}^{-1}$ for $\mathrm{Zn}$. They were calculated as three ${ }_{264}$ and ten times the standard deviation of the blank sample noise counts, respectively, after extraction ${ }_{265}$ and analysis. The software used for data treatment was PlasmaLab v.2.6.2.

266

${ }_{267} 2.8$ Quality Assurance and Quality control (QA/QC)

268

${ }_{269}$ For GC/MS and ICP/MS analysis, control samples were used to evaluate analysis performance. ${ }_{270}$ Standard solutions were analyzed between soil samples to verify that calibration curves were valid ${ }_{271}$ throughout the analysis and that the instrument was not affected by the matrix of the samples ${ }_{272}$ (Continuing Calibration Verification). For GC/MS and ICP/MS analysis, internal standard calibration ${ }_{273}$ was used. In both cases, recoveries of the compounds from the standard solutions were accepted within

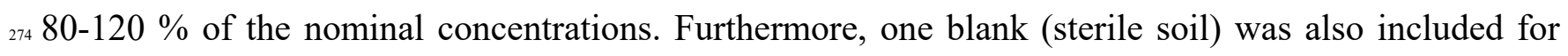
${ }_{275}$ each day of microcosms' analysis to control that the spiked PAHs concentration remained constant ${ }_{276}$ until the completion of the experiments.

277

${ }_{278} 3$ Results and discussion

${ }_{280} 3.1$ Determination of bioavailable fraction of metals in the soil

281

${ }_{282}$ The analysis of the exchangeable fraction (accepted as the bioavailable fraction) in the native soil ${ }_{283}$ revealed a concentration of $0.15 \pm 0.01 \mu \mathrm{g} \mathrm{g}^{-1}$ of $\mathrm{Cr}, 0.50 \pm 0.05 \mu \mathrm{g} \mathrm{g}^{-1}$ of $\mathrm{Mn}, 0.010 \pm 0.001 \mu \mathrm{g} \mathrm{g}^{-1}$ of Co, ${ }_{284} 0.05 \pm 0.01 \mu \mathrm{g} \mathrm{g}^{-1}$ of $\mathrm{Ni}, 0.25 \pm 0.01 \mu \mathrm{g} \mathrm{g}^{-1}$ of $\mathrm{Cu}, 0.50 \pm 0.07 \mu \mathrm{g} \mathrm{g}^{-1}$ of $\mathrm{Zn}$ and $0.150 \pm 0.003 \mu \mathrm{g} \mathrm{g}^{-1}$ of $\mathrm{Pb}$. ${ }_{285}$ The total content of bioavailable metals was $1.61 \pm 0.05 \mu \mathrm{g} \mathrm{g}^{-1}$. Therefore, these seven metals were 
${ }_{286}$ Selected for the present study. $\mathrm{Zn}$ and $\mathrm{Mn}$ are the most concentrated metals in this fraction, whereas Ni ${ }_{287}$ and Co are the less concentrated, with a difference of one order of magnitude.

288

${ }_{289} 3.2$ Microbiological growth assessment at different concentrations of metals

290

${ }_{291}$ Microbiological assays were prepared, as indicated in section 2.3, with the concentrations specified in ${ }_{292}$ Table 1 considering the bioavailable concentrations found in soil. After incubation, the number of ${ }_{293}$ colony forming units (CFU) $\mathrm{g}^{-1}$ was determined in each soil (Table 1). The number of CFU did not 294 vary significantly after exposing bacterial communities to the eight different total concentrations of ${ }_{295}$ metals $(p<0.05)$. This indicates that the growth and abundance of tolerant species were not affected ${ }_{296}$ either by the metals introduced or by the nitrate/sulfate content (considering that these results do not ${ }_{297}$ give any information about bacterial diversity). Therefore, 10, 250 and 500 times the bioavailable ${ }_{298}$ metals found in soil (named x10, x250 and x500, respectively) were selected as the three metal ${ }_{299}$ contamination levels to conduct the experiments of PAHs biodegradation. Lower spiking limits were ${ }_{300}$ omitted because, in previous experiments, no significant influence on PAHs biodegradation was ${ }_{301}$ observed. The higher spiking limit was also omitted because it contained amounts of some metals ${ }_{302}$ above the maximum allowed concentration in soils according to the current Spanish legislation ${ }_{303}$ (Spanish Government, 2013). After spiking the soil with metals, $\mathrm{pH}$ was verified and adjusted to the ${ }_{304}$ original value if necessary.

305

${ }_{306} 3.3$ PAHs biodegradation at different concentrations of metals

307

${ }_{308}$ The results of PAHs biodegradation at different concentrations of metals are shown in Figure 3. First, ${ }_{309}$ it can be observed that standard deviation values are very low (relative standard deviations - RSD ${ }_{310}$ below $5 \%$ ), which means that the homogenization of microcosms was optimally performed. Secondly, 
${ }_{311}$ the analysis of the blank (sterile soil spiked with PAHs and x250 level of metals) demonstrates that the ${ }_{312}$ initial concentration of PAHs found in microcosms after spiking remained constant throughout the ${ }_{313}$ sixty days of the experiment, proving that the degradation observed in the other microcosms (not ${ }_{314}$ sterilized) was mainly due to biological activity of the native soil and not to other kind of chemical ${ }_{315}$ reactions, volatilization or photooxidation (abiotic losses). On the other hand, the analysis of duplicates ${ }_{316}$ of some microcosms (at the intermediate level of metals) did not show significant differences $(\mathrm{p}<0.05)$ ${ }_{317}(\mathrm{RSD}$ below $8 \%$ ), which indicates that the preparation of microcosms was also reproducible.

${ }_{318}$ Regarding PAH biodegradation kinetics, zero order, first order and second order were tested (Thiele${ }_{319}$ Bruhn and Brümmer, 2005). The best fit was generally found with equations of first order for all PAHs ${ }_{320}\left(0.782 \leq \mathrm{R}^{2} \leq 0.956\right)$ at all metals concentrations, with the exception of $\mathrm{BbF}$ and $\mathrm{BaP}$ which fit better ${ }_{321}$ with the zero-order kinetics model $\left(0.672 \leq \mathrm{R}^{2} \leq 0.960\right)$, with a quite linear and very slow dissipation. ${ }_{322}$ The correlation coefficients with the logistic fitting and first order model, degradation rates and ${ }_{323}$ calculated and experimental DT50 values (time required for $50 \%$ dissipation) are shown in Table 2. ${ }_{324}$ Figure 3 shows different degradation profiles which can be divided into two groups: Phe, Fluo and Pyr ${ }_{325}$ were together in the first group and $\mathrm{BbF}$ and $\mathrm{BaP}$ in the second one. The variation of the degradation at ${ }_{326}$ the distinct levels of metals is more important for the first three PAHs than for BbF and BaP.

${ }_{327}$ For Phe, Fluo and Pyr, in general, less degradation of PAHs was observed when the concentration of ${ }_{328}$ metals increased (Figure $3 \mathrm{a}, 3 \mathrm{~b}$ and $3 \mathrm{c}$ ). This is also deduced from data shown in Table 2 with ${ }_{32}$ decreasing degradation rate constants from the non-spiked to x500 microcosms for Phe (from 0.1383 ${ }_{330}$ day $^{-1}$ to 0.0118 day $^{-1}$ ), Fluo (from 0.1211 day $^{-1}$ to 0.0008 day $^{-1}$ ) and Pyr (from 0.1021 day $^{-1}$ to 0.0003 ${ }_{331}$ day $^{-1}$ ) and increasing DT50 values. Also, in the case of these three compounds, no significant ${ }_{332}$ differences between the degradation in the microcosms non-spiked with metals and the lower level of ${ }_{333}$ metal concentration $(\mathrm{x} 10)$ were observed in almost all days of the study (means were compared using ${ }_{334}$ Student's t-test , $\left.\mathrm{p}<0.05\right)$. Possibly, the metal concentration introduced did not represent a high toxicity ${ }_{335}$ for the living microorganisms in the soil. Degradation rates were quite similar in the non-spiked and 
${ }_{336}$ X10 microcosms for Phe $\left(k=0.1383\right.$ day $^{-1} / 0.1442$ day $^{-1}$, respectively), Fluo $\left(k=0.1211\right.$ day $^{-1} / 0.1174$ day $^{-}$ ${ }_{337}^{1}$, respectively) and $\operatorname{Pyr}\left(k=0.1021 \mathrm{day}^{-1} / 0.1051 \mathrm{day}^{-1}\right.$, respectively). Nonetheless, after 10 days, 77 and ${ }_{338} 79 \%$ of Phe was degraded in the non-spiked and x10 microcosms, respectively while Pyr (22 and 25 ${ }_{339} \%$ ) and Fluo (16 and $24 \%$ ) were degraded more slowly, as can be also observed from the experimental ${ }_{340}$ DT50 values for Phe (8 days) and Fluo and Pyr (12 days). For Fluo and Pyr, degradation percentages ${ }_{341}$ after 15 days were higher, between $84-90 \%$, for both compounds in both microcosms (Phe was ${ }_{342}$ degraded up to a $95-96 \%$, already). Contrary to the biodegradation of PAHs at low levels of metals, ${ }_{343}$ Stronger differences can be seen at the higher metals concentration levels (x250 and x500). In x250 ${ }_{344}$ microcosms, the degradation of Phe was much slower than the observed before $\left(k=0.040\right.$ days $^{-1}$; ${ }_{345}$ DT50=17 days), arriving only to $80 \%$ degradation after 21 days of incubation, whereas at lower levels ${ }_{346}$ of metals this value was achieved after just 10 days (at 21 days, only $19 \%$ of Phe has been degraded at ${ }_{347} \mathrm{X} 250$ ). Nevertheless, after 60 days, $87 \%$ of Phe was metabolized, which is significantly a higher ${ }_{348}$ degradation percentage than the observed for Fluo $(60 \%)$ and Pyr $(53 \%)$ at the same time $(\mathrm{p}<0.05)$. ${ }_{349}$ Fluo and Pyr degrade similarly at $\mathrm{x} 250$ microcosms, with $k=0.0169$ days $^{-1} / 0.0146$ days $^{-1}$ and ${ }_{350}$ theoretical DT50=41/47 days, respectively. Finally, non-significant variation of the concentration of ${ }_{351}$ Fluo and Pyr was detected after two months in $\mathrm{x} 500$ microcosms in relation to the initial level $(\mathrm{p}<0.05)$ ${ }_{352}$ and only $30 \%$ of Phe was eliminated. This also explains the low correlation coefficient found for Fluo ${ }_{353}$ and Pyr at this higher amount of metals, for any of the kinetic models tested $\left(\mathrm{R}^{2}<0.624\right.$ for Fluo, and ${ }_{354} \mathrm{R}^{2}<0.128$ for Pyr).

${ }_{355}$ All these results agree with the known ability of many microorganisms to degrade low weight PAH ${ }_{356}$ (LWPAH) faster than heavy weight PAHs (HWPAH). PAHs in sediments are rather immobile as a ${ }_{357}$ result of their hydrophobic nature which inhibits them from dissolving in water. PAHs solubility is ${ }_{358}$ inversely related to their molecular weights, which make lighter PAHs more soluble and consequently ${ }_{359}$ more bioavailable (Thorsen et al., 2004). The fact that Phe has been observed to degrade faster than ${ }_{360}$ Fluo and Pyr could be related to differences in solubility and, according to some authors, to the 
${ }_{361}$ existence of a "K" and "bay" regions in the Phe structure. This would confer Phe with an optimum ${ }_{362}$ conformation for the anchorage of multiple enzymes involved in the oxidation of this kind of ${ }_{363}$ compounds (Zhang et al., 2006; Kuppusamy, 2016b).

${ }_{364}$ Therefore, the degradation rates of Phe, Fluo and Pyr decreased when the concentration of metals ${ }_{365}$ increased, showing a significant effect when mixed pollutants are present in soil (PAHs and metals), ${ }_{366}$ affecting negatively the microorganisms' activity present in soils. Previous studies found in the ${ }_{367}$ literature show that this effect is dependent on the native soil microorganisms' composition ${ }_{368}$ (Kuppusamy et al., 2016b). Also, Fluo and Pyr had a comparable behavior at all levels of metals ${ }_{369}$ concentration and showed strong correlated kinetic parameters (Table 2). Other authors saw this ${ }_{370}$ parallel behavior between the former compounds in biodegradation studies involving mixtures of ${ }_{371}$ PAHs and five different soils (without metal consideration) (Crampon et al., 2014), and also for Pyr 372 biodegradation in soils with different microorganism' mixtures content and in presence of metals ${ }_{373}$ (Kuppusamy et al., 2016b).

${ }_{374}$ On the opposite, the biodegradation of $\mathrm{BbF}$ and $\mathrm{BaP}$ (HWPAHs) seems not to be affected by the ${ }_{375}$ different concentrations of metals introduced (Figure 3d and 3e), probably due to the little ability of ${ }_{376}$ the bacterial consortia to efficiently degrade them under any circumstances (compared to other ${ }_{377}$ previous studies, Deary et al., 2016; Kuppusamy et al., 2016a). After 60 days, only 29, 22, 16 and 19 $378 \%$ of $\mathrm{BbF}$ was degraded in the non-spiked x10, x250 and x500 microcosms, respectively, and the ${ }_{379}$ results were not much different for $\mathrm{BaP}$ either $(32,30,27$ and $36 \%$, respectively) at the same time. ${ }_{380}$ After 60 days, no significant differences in the concentration of BaP were found either between the ${ }_{381}$ non-spiked and $\mathrm{x} 10$ or between $\mathrm{x} 10$ and $\mathrm{x} 250$ microcosms $(\mathrm{p}<0.05)$. Although the concentration of ${ }_{382} \mathrm{BaP}$ in $\mathrm{x} 500$ was statistically different from the other microcosms after 60 days, the biodegradation ${ }_{383}$ profile of $\mathrm{BaP}$ in each level of metals introduced was not as sharp as it was for Phe, Fluo and Pyr. ${ }_{384}$ Analogous judgment could be used to describe the biodegradation profile of BbF in each level of ${ }_{385}$ metals, where no significant differences were observed either between $\mathrm{x} 250$ and $\mathrm{x} 500$ or between $\mathrm{x} 10$ 
${ }_{386}$ and x500 microcosms. These conclusions can also be drawn from the comparable degradation rates ${ }_{387}$ and theoretical DT50 values for BbF (mean $\mathrm{k}=0.0039$ days-1, mean DT50=191 days) and BaP (mean ${ }_{388} \mathrm{k}=0.0055$ days -1 , mean DT50=126 days). These low degradation rates confirm the recalcitrant nature ${ }_{389}$ of these heavier PAHs. This is principally explained by the progressive decrease in solubility and 390 increase in hydrophobicity (therefore, less bioavailability) of PAHs as their molecular weight ${ }_{391}$ increases. Also, it is widely accepted that the higher the molecular weight of PAHs the lower the ${ }_{392}$ degradation ability of microorganisms, because other simpler organic forms, including LWPAHs, are ${ }_{393}$ more suitable to be used as a sole carbon energy source. This competitive inhibition is particularly ${ }_{394}$ important when microorganisms such as bacteria use enzymes with non-specific actives sites for PAHs ${ }_{395}$ breakdown (Stroud et al., 2007; Wang et al., 2009; Abdel-Shafy and Mansour, 2016). HWPAHs can ${ }_{396}$ also represent a carbon source for microorganisms but only a few can efficiently degrade them, and ${ }_{397}$ often by co-metabolism. Another reason of the poor degradation of HWPAHs is the low amounts of 398 bacteria in soils able to degrade them (Kästner et al., 1994) and the lack of enzymatic induction, which 399 is more complicated due to their bigger size and more complex conformation. This makes PAHs less ${ }_{400}$ accessible for the active centers of the enzymes involved in the metabolism of many microorganisms. ${ }_{401}$ In fact, $\mathrm{BaP}$ and $\mathrm{BbF}$ show better correlation with a zero order kinetics model, typically observed in 402 biodegradations profile which undergo through the co-metabolism phenomena.

${ }_{403}$ Co-metabolism can be defined as a non-specific enzymatic reaction between a new substrate that ${ }_{404}$ competes with a primary substrate of similar structure for the active site of the enzyme (Stroud et al., ${ }_{405}$ 2007). This phenomenon explains that degradation of certain HWPAHs can be enhanced by the ${ }_{406}$ presence of simpler carbon source structures such as LWPAHs (e.g. Phe), which would not occur (or ${ }_{407}$ Would be lower) in their absence. It was reported that the presence of Phe enhanced the biodegradation ${ }_{408}$ of Anth, Flu and Pyr (Yuan et al., 2001) and also contributed to the increase in biomass when acting as ${ }_{409}$ a co-substrate for the co-metabolism of Chry, Fluo and Pyr (Hwang and Cutright, 2003; Iqwo-Ezipke, ${ }_{410} 2010$ ), as could have happened in this study. It can be seen in Figure 3 that the biodegradation of Fluo 
${ }_{411}$ and Pyr started always later than Phe (at any of the concentrations of metals where degradation is ${ }_{412}$ observed). On the other hand, the degradation rates of Fluo and Pyr seem to decrease when Phe was ${ }_{413}$ nearly completely metabolized (easy to observe in x250 microcosms after 30 days or in non-spiked or ${ }_{414}$ X10 microcosms after 15 days). However, more consistent data should be collected if the objective of ${ }_{415}$ the study were to support a co-metabolism effect on the biodegradation of $\mathrm{BaP}$ and $\mathrm{BbF}$.

${ }_{416}$ About the degradation profiles (for those cases were degradation is significantly observed; i.e. non${ }_{417}$ spiked, x10 and x250 microcosms), three different phases can be clearly distinguished. The first one, ${ }_{418}$ generally comprising the first 7 days of the study, shows latent or very low microbiological activity ${ }_{419}$ and probably corresponds to an adaptation phase (lag-phase) of the microorganisms in response to the ${ }_{420}$ Stress caused by the introduced contamination (metals and PAHs), which agrees with previous ${ }_{421}$ observations by other authors (Wen et al., 2011). It can be noted that the initial lag-phase of concerned ${ }_{422}$ compounds was not excluded from the kinetic models described previously because this phase was ${ }_{423}$ relatively short and did not have any significant impact on the first order modelling. Bacterial ${ }_{424}$ communities exhibit different tolerance to contamination and those which are resistant evolve to a ${ }_{425}$ Second phase, where biodegradation takes place very quickly (7-30 days). Finally, the third phase ${ }_{426}$ consists in the achievement of a plateau state, where biodegradation rates stabilize or decrease very ${ }_{427}$ slowly. This slow biodegradation of residual PAHs is generally assigned to a lower PAH ${ }_{428}$ bioavailability, depending on the contact time between lipophilic contaminants and soils particles ${ }_{429}$ (especially for HWPAHs, as previously seen by Deary et al, 2016). Indeed, at this final stage, ${ }_{430}$ degrading microorganisms are present in soils and have shown an important degrading activity on ${ }_{431}$ certain PAHs, but strong and almost irreversible interactions take place between residual PAHs and ${ }_{432}$ soil organic matter which prevent contaminants from desorption and subsequent absorption by ${ }_{433}$ microorganisms.

${ }_{434}$ These biodegradation profiles were also observed by some authors who stated a dependency between ${ }_{435}$ the adaptation time required by bacterial communities and the concentration of PAHs supplemented, 
${ }_{436}$ establishing a direct relationship between the number of $\mathrm{CFU} \mathrm{g}^{-1}$ and the degradation percentage of ${ }_{437}$ these compounds (Khan et al., 2009; Wen et al., 2011.). In our study, the number of $\mathrm{CFU} \mathrm{g}^{-1}$ was ${ }_{438}$ neither correlated with the lag-phase duration nor with the level of metals introduced in the ${ }_{439}$ microcosms. In fact, the spiked metal level had no influence on the total number of soil ${ }_{440}$ microorganisms in the concentration range studied (Table 1), but probably had more influence on the ${ }_{441}$ relative abundance of specific PAH-degrading strains, which represents generally less than $1 \%$ of the ${ }_{442}$ cultivable soil bacteria (Crampon et al., 2014).

443

${ }_{444}$ In the present work, there is no evidence that the mixtures of metals enhance PAHs biodegradation but ${ }_{445}$ the opposite. Nonetheless, the purpose of the research cited above was the evaluation of metal/PAH ${ }_{446}$ interactions individually, and not to follow their behavior as multiple mixtures, which is the present ${ }_{447}$ purpose. To study all contaminants together is certainly difficult since soils contain high numbers of ${ }_{448}$ other compounds at many different concentrations, leading to complex interactions between them. ${ }_{449}$ Furthermore, PAHs' partition between the aqueous phase in contact with the soil phases, each ${ }_{450}$ possessing a different degree of bioaccessibility, can also affect their biodegradation (Deary et al., $\left.{ }_{451} 2016\right)$.

${ }_{452}$ The present work demonstrates that studies, even if performed under controlled conditions, must ${ }_{453}$ enforce to be more representative of real conditions in order to better understand in-field ${ }_{454}$ bioremediation processes by natural attenuation.

455

${ }_{456} 4$ Conclusions

457

${ }_{458}$ A study about mixed pollutants has been performed to assess the influence of different concentrations ${ }_{459}$ of seven metals on the biodegradation of five PAHs during sixty days by means of the analysis of soil${ }_{460}$ based microcosms. 
${ }_{461}$ The study of the interaction of mixed contaminants in a complex environmental matrix has shown that ${ }_{462}$ the different levels of metals caused a significant negative effect on the biodegradation capability of ${ }_{463}$ the 3-4 rings PAHs Phe, Fluo and Pyr, with decreased dissipation constant rates and increased DT50 ${ }_{464}$ values. No effect was detected on the 5-rings PAHs BbF and BaP, which are recalcitrant PAHs ${ }_{465}$ (HWPAHs) and showed very low dissipation rates and the highest DT50 values even in the absence of ${ }_{466}$ metals. Also, it has been seen that degradation rates in the first order kinetics approach vary ${ }_{467}$ significantly depending on the nature of PAHs and the concentration of metals introduced in the ${ }_{468}$ microcosms. Dissipation profiles of biodegraded PAHs consisted of few phases, starting with a latency ${ }_{469}$ period and then consistently being degraded until reaching a plateau state.

${ }_{470}$ It would be interesting to conduct further studies to evaluate whether the impact on PAH ${ }_{471}$ biodegradation was caused by one single metal or by combinations of them.

${ }_{472}$ These results show the importance of the decontamination of some metal polluted areas if PAHs ${ }_{473}$ bioremediation activities are to be performed in natural soils, particularly those carried out by ${ }_{474}$ microbiological processes.

475

${ }_{476}$ Acknowledgements

477

${ }_{478}$ Authors acknowledge the financial support provided by Spanish Ministry MINECO (CTM2012${ }_{479}$ 30970, CTM2015-65414-C2-1-R). O. Baltrons acknowledges the research support by Universitat ${ }_{480}$ Autònoma de Barcelona (P.I.F. Grant 403-03-1/09) and ORQUE SUDOE SOE3-P2-F591.

481

${ }_{482}$ References

483

${ }_{484}$ Bakircioglu, D., Bakircioglu-Kurtulus, Y.B., Ibar, H., 2011. Comparison of extraction procedures for ${ }_{485}$ assessing soil metal bioavailability of two wheat grains. Clean-Soil, Air, Water 39, 728-734. 
${ }_{487}$ Baldrian, P., Wiesche, C., Gabriel, J., Nerud, F., Zadrazil, F., 2000. Influence of cadmium and mercury ${ }_{488}$ on activities of ligninolytic enzymes and degradation of polycyclic aromatic hydrocarbons by ${ }_{489}$ Pleurotus ostreatus in soil. Appl. Environ. Microbiol. 66, 2471-2478.

490

${ }_{491}$ Baltrons, O., López-Mesas, M., Palet, C., Le Derf, F., Portet-Koltalo, F., 2013. Molecularly imprinted ${ }_{492}$ polymer - liquid chromatography/fluorescence for the selective clean-up of hydroxylated polycyclic ${ }_{493}$ aromatic hydrocarbons in soils. Anal. Methods 5, 6297-6305.

494

${ }_{495}$ Blum, W.E.H., Horak, O., Mentler, A., Puschenreiter, M., 2009. Trace metals, in: Sabljic, A. (Ed.), ${ }_{496}$ Environmental and Ecological Chemistry, Volume 2, EOLSS Publishers Company Ltd., Oxford, pp. 497 156-164.

498

${ }_{499}$ Biswas, B., Sarkar, B., Mandal, A., Naidu, R., 2015. Heavy metal-immobilizing organoclay facilitates ${ }_{500}$ polycyclic aromatic hydrocarbon biodegradation in mixed-contaminated soil. J. Hazard. Mater. 298, ${ }_{501} 129-137$.

502

${ }_{503}$ Boyle, D., Wiesner, C., Richardson, A., 1998. Factors affecting the degradtion of polyaromatic ${ }_{504}$ hydrocarbons in soil by white-rot fungi. Soil. Biol. Biochem. 30, 873-882.

505

${ }_{506}$ Chen, M., Xu, P., Zeng, G., Yang, C., Huang, D., Zhang, J., 2015. Bioremediation of soils ${ }_{507}$ contaminated with polycyclic aromatic hydrocarbons, petroleum, pesticides, chlorophenols and heavy ${ }_{508}$ metals by composting: Applications, microbes and future research needs. Biotechnol. Adv. 33, 745${ }_{509} 755$. 
${ }_{511}$ Crampon, M., Bureau, F., Akpa-Vinceslas, M., Bodilis, J., Machour, N., Le Derf, F., Portet-Koltalo, ${ }_{512}$ F., 2014. Correlations between PAH bioavailability, degrading bacteria, and soil characteristics during ${ }_{513}$ PAH biodegradation in five diffusely contaminated dissimilar soils. Environ. Sci. Pollut. Res. Int. 21, ${ }_{514} 8133-8145$.

515

${ }_{516}$ Deary, M.E., Ekumankama, C.C., Cummings, S.P., 2016. Development of a novel kinetic model for ${ }_{517}$ the analysis of PAH biodegradation in the presence of lead and cadmium co-contaminants. J. Hazard. ${ }_{518}$ Mater. 307, 240-252.

519

${ }_{520}$ Fernández-Luqueño, F., Valenzuela-Encinas, C., Marsch, R., Martínez-Suárez, C., Vázquez-Núnez, E., ${ }_{521}$ Dendooven, L., 2011. Microbial communities to mitigate contamination of PAHs in soil - possibilities ${ }_{522}$ and challenges: a review. Environ Sci Pollut Res. 18, 12-30.

523

${ }_{524}$ Fijałkowska, S., Lisowska, K., Długoński, J., 1998. Bacterial elimination of polycyclic aromatic ${ }_{525}$ hydrocarbons and heavy metals. J. Basic. Microbiol. 38, 361-369.

526

${ }_{527}$ Giller, K.E., Witter, E., McGrath, S.P., 1998. Toxicity of heavy metals to microorganisms and ${ }_{528}$ microbial processes in agricultural soils: A review. Soil. Biol. Biochem. 30, 1389-1414.

529

${ }_{530}$ Huertos, E.G., Baena, A.R., 2008. Contaminación de suelos por metales pesados. Macla 10, 48-60.

531

${ }_{532}$ Abdel-Shafy, H.I., Mansour, M.S.M., 2016. A review on polycyclic aromatic hydrocarbons: Source, ${ }_{533}$ environmental impact, effect on human health and remediation. Egypt. J. Pet. 25, 107-123. 
${ }_{535}$ Hwang, S., Cutright, T.J., 2003. Effect of expandable clays and cometabolism on PAH ${ }_{536}$ biodegradability. Environ. Sci. Pollut. Int. 10, 277-280.

537

${ }_{538}$ Igwo-Ezikpe, M.N., Gbenle, O.G., Ilori, M.O., Okpuzor, J., Osuntoki, A.A., 2010. Mixture of high ${ }_{539}$ molecular weight polycyclic aromatic hydrocarbons biodegradation by tropical bacteria and via co${ }_{540}$ metabolism with phenanthrene. Res. J. Environ. Sci. 4, 317-326.

541

${ }_{542}$ Janbandhu, A., Fulekar, M., 2011. Biodegradation of phenanthrene using adapter microbial consortium ${ }_{543}$ isolated from petrochemical contaminated environment. J. Hazard. Mater. 187, 333-340.

${ }_{545}$ Jonsson, S., Persson, Y., Frankki, S., Van Bavel, B., Lundstedt, S., Haglund, P., Tysklind, M., 2007. ${ }_{546}$ Degradation of polycyclic aromatic hydrocarbons (PAHs) in contaminated soils by Fenton's reagent: a ${ }_{547}$ multivariate evaluation of the importance of soil characteristics and PAH properties. J. Hazard. Mater. ${ }_{548} 149,86-96$.

549

${ }_{550}$ Kabata-Pendias, A., 2010. Trace Elements in Soils and Plants, forth ed. CRC Press, Boca Raton.

551

${ }_{552}$ Kästner, M., Breuer-Jammali, M., Mahro, B., 1994. Enumeration and characterization of the soil ${ }_{553}$ microflora from hydrocarbon-contaminated soil sites able to mineralize polycyclic aromatic ${ }_{554}$ hydrocarbons (PAH). Appl. Microbiol. Biot. 41, 267-273.

555

${ }_{556}$ Ke, L., Luo, L., Wang, P., Luan, T., Tam, N.F.Y., 2010. Effects of metals on biosorption and ${ }_{557}$ biodegradation of mixed polycyclic aromatic hydrocarbons by a freshwater green alga Selenastrum s58 capricornutum. Bioresource Technol. 101, 6950-6961. 
${ }_{560}$ Khan, S., El-Latif Hesham, A., Qing, G., Shuang, L., He, J., 2009. Biodegradation of pyrene and ${ }_{561}$ catabolic genes in contaminated soils cultivated with Lolium multiflorum. J. Soil. Sediments 9, 482562491.

563

${ }_{564}$ Kobayashi, T., Murai, Y., Tatsumi, K., Iimura, Y., 2009. Biodegradation of polycyclic aromatic ${ }_{565}$ hydrocarbons by Sphingomonas sp. enhanced by water-extractable organic matter from manure ${ }_{566}$ compost. Sci. Total Environ. 407, 5805-5810.

567

${ }_{568}$ Kuppusamy, S., Thavamani, P., Megharaj, M., Lee, Y.B., Naidu, R., 2016. Kinetics of PAH ${ }_{569}$ degradation by a new acid-metal-tolerant Trabulsiella isolated from the MGP site soil and ${ }_{570}$ identification of its potential to fix nitrogen and solubilize phosphorous. J. Hazard. Mater. 307, 99-107, ${ }_{571}$ a.

572

${ }_{573}$ Kuppusamy, S., Thavamani, P., Megharaj, M., Naidu, R., 2016. Biodegradation of polycyclic aromatic ${ }_{574}$ hydrocarbons (PAHs) by novel bacterial consortia tolerant to diverse physical settings - Assessments ${ }_{575}$ in liquid- and slurry-phase systems. Int. Biodeter. Biodegr. 108, 149-157, b.

576

${ }_{577}$ Landi, L., Renella, G., Moreno, J.L., Falchini, L., Nannipieri, P., 2000. Influence of cadmium on the ${ }_{578}$ metabolic quotient, L-:D-glutamic acid respiration ratio and enzyme activity: microbial biomass ratio ${ }_{579}$ under laboratory conditions. Biol. Fertil. Soils 32, 8-16. 
${ }_{581}$ Moreau, C.J., Klerks, P.L., Haas, C.N., 1999. Interaction between phenanthrene and zinc in their ${ }_{582}$ toxicity to the sheepshead minnow (Cyprinodon variegatus). Arch. Environ. Contam. Toxicol. 37, ${ }_{583} 251-257$.

584

${ }_{585}$ Niepceron, M., Martin-Laurent, F., Crampon, M., Portet-Koltalo, F., Akpa-Vinceslas, M., Legras, M., ${ }_{586}$ Bru, D., Bureau, F., Bodilis, J., 2013. GammaProteobacteria as a potential bioindicator of a multiple ${ }_{587}$ contamination by polycyclic aromatic hydrocarbons (PAHs) in agricultural soils. Environ. Pollut. 180, 588 199-205.

589

${ }_{590}$ Obuekwe, I.S., Semple, K.T., 2013. Impact of $\mathrm{Zn}$ and $\mathrm{Cu}$ on the development of phenanthrene ${ }_{591}$ catabolism in soil. Environ. Monit. Assess. 185, 10039-10047.

592

${ }_{593}$ Samanta, K.S., Singh, O.V., Jain, R.K., 2002. Polycyclic aromatic hydrocarbons: environmental ${ }_{594}$ pollution and bioremediation. Trends Biotechnol. 20, 243-248.

595

${ }_{596}$ Shen, G., Lu, Y., Hong, J., 2006. Combined effect of heavy metals and polycyclic aromatic ${ }_{597}$ hydrocarbons on urease activity in soil. Ecotoxicol. Environ. Saf. 63, 474-480.

598

${ }_{599}$ Shen, G., Lu, Y., Zhou, Q., Hong, J., 2005. Interaction of polycyclic aromatic hydrocarbons and heavy ${ }_{600}$ metals on soil enzyme. Chemosphere $61,1175-1182$.

601

${ }_{602}$ Siddiqi, M.A., Yuan, Z.X., Honey, S.A., Kumar, S., Sikka, H.C., 2002. Metabolism of PAHs and ${ }_{603}$ methyl-substituted PAHs by Sphingomonas paucimobilis strain EPA 505. Polycycl. Aromat. Compd. ${ }_{604} 22,621-630$. 
${ }_{606}$ Sokhn, J., De Leij, F.A.A.M., Hart, T.D., Lynch, J. M., 2001. Effect of copper on the degradation of ${ }_{607}$ phenanthrene by soil microorganisms. Lett. Appl. Microbiol. 33, 164-168.

${ }_{609}$ Spanish Government, Real Decreto 1310/1990. http://www.boe.es/ boe/dias/1990/11/01/ pdfs/A32339${ }_{610}$ 32340.pdf, (accessed 5 March 2013).

611

${ }_{612}$ Stroud, J.L., Paton, G.I., Semple, K.T., 2007. Importance of chemical structure on the development of ${ }_{613}$ hydrocarbon catabolism in soil. FEMS Microbiol. Lett. 272, 120-126.

${ }_{615}$ Subashchandrabose, S.R., Megharaj, M., Venkateswarlu, K., Naidu, R., 2015. Interaction effects of ${ }_{616}$ polycyclic aromatic hydrocarbons and heavy metals on a soil microalga, Chlorococcum sp. MM11. ${ }_{617}$ Environ. Sci. Pollut. Res. Int. 22, 8876-8889.

${ }_{619}$ Tam, Y.W.F., Takeda, K., Sakugawa, H., 2008. Exploring the correlation of particulate PAHs, sulfur ${ }_{620}$ dioxide, nitrogen dioxide and ozone, A preliminary study. Water Air Soil Pollut. 194, 5-12.

621

${ }_{622}$ Thavamani, P., Malik, S., Beer, M., Megharaj, M., Naidu, R., 2012. Microbial activity and diversity in ${ }_{623}$ long-term mixed contaminated soils with respect to polyaromatic hydrocarbons and heavy metals. J. ${ }_{624}$ Environ. Manage. 99, 10-17.

625

${ }_{626}$ Thiele-Bruhn, S., Brümmer, G., 2005. Kinetics of polycyclic aromatic hydrocarbon (PAH) degradation ${ }_{627}$ in long-term polluted soils during bioremediation. Plant Soil 275, 31-42. 
${ }_{629}$ Tobiszewski, M., Namieśnik, J., 2012. PAH diagnostic ratios for the identification of pollution ${ }_{630}$ emission sources. Environ. Pollut. 162, 110-119.

631

${ }_{632}$ Wang, C., Sun, H., Li, J., Li, Y., Zhang, Q., 2009. Enzyme activities during degradation of polycyclic ${ }_{633}$ aromatic hydrocarbons by white rot fungus Phanerochaete chrysosporium in soils. Chemosphere 77, ${ }_{634} 733-738$.

635

${ }_{636}$ Watanabe, K., 2001. Microorganisms relevant to bioremediation. Curr. Opin. Biotechnol. 12, 237-256.

637

${ }_{638}$ Wentworh, C.K., 1922. A scale of grade and class terms for clastic sediments. J. Geol. 30, 377-392.

639

${ }_{640}$ Wen, J., Gao, D., Zhang, B., Liang, H., 2011. Co-metabolic degradation of pyrene by indigenous ${ }_{641}$ white-rot fungus Pseudotrametes gibbosa from the northeast China. Int. Biodeter. Biodegr. 65, 600${ }_{642} 604$.

643

${ }_{644}$ Wilson, S.C., Jones, K., 1993. Bioremediation of soil contaminated with polynuclear aromatic ${ }_{645}$ hydrocarbons (PAHs): a review. Environ. Pollut. 81, 229-249.

646

${ }_{647}$ Wuana, R.A., Okieimen, F.E., 2011. Heavy metals in contaminated soils: A review of sources, ${ }_{648}$ chemistry, risks and best available strategies for remediation. ISRN Ecology, 1-20.

649

${ }_{650}$ Yuan, S.Y., Chang, J.S., Yen, J.H., Chang, B.V., 2001. Biodegradation of phenanthrene in river ${ }_{651}$ sediment. Chemosphere 43, 273-278. 
${ }_{653}$ Zehetner, F., Rosenfellner, U., Mentler, A., Gerzabek, M.H., 2009. Distribution of road salt residues, ${ }_{654}$ heavy metals and polycyclic aromatic hydrocarbons across a highway-forest interface. Water Air Soil ${ }_{655}$ Pollut. 198, 125-132.

656

${ }_{657}$ Zhang, X.X., Cheng, S.P., Zhu, J.C., Sun, S.L., 2006. Microbial PAH-degradation in soil: degradation ${ }_{658}$ pathways and contributing factors. Pedosphere 16, 555-565.

659

${ }_{660}$ Zhou, L., Li, H., Zhang, Y., Han, S., Xu, H., 2016. Sphingomonas from petroleum-contaminated soils ${ }_{661}$ in Shenfu, China and their PAHs degradation abilities. Braz. J. Microbiol. 47, 271-278. 